\title{
SISTEMA DE MONITORAMENTO DE LEITO - MONILEITO
}

\author{
L. A. S. Araujo*, L. G. B. Fontes*, V. H. F. Morales*, A. B. Azar*, M. M. M. S. Mateus*, F. F. \\ Diniz* e A. C. Patrocinio* \\ *Faculdade de Engenharia Elétrica, Universidade Federal de Uberlândia, Uberlândia, Brasil \\ e-mail: laureane.almeidasa@gmail.com
}

\begin{abstract}
Resumo: Este artigo tem por objetivo apresentar o desenvolvimento de um software para o monitoramento eletrônico de leitos de um posto de saúde. O programa estará instalado no computador de uma sala restrita ao corpo médico e somente profissionais cadastrados poderão acessá-lo para visualizar, inserir ou alterar dados referentes à ocupação do leito. O sistema foi desenvolvido a fim de tornar a troca de turnos da equipe médica mais eficiente, permitindo gerir os leitos de forma rápida e prática.
\end{abstract}

Palavras-chave: Sistema de monitoramento de leito, consulta a leitos, gerenciamento de leitos.

\begin{abstract}
This article aims to present the development of an electronic monitoring software for beds in a health center. The program will be located on the computer in a restricted room where just the medical staff and only registered professionals can access it, enter or change data on the occupation of the bed. The system was developed to make the shift change more efficient, allowing managing beds quickly and conveniently.
\end{abstract}

Keywords: Bed monitoring system, check the beds, management beds.

\section{Introdução}

A troca de turno do corpo médico em um estabelecimento de saúde é uma prática realizada com o princípio de passar informações sobre as intercorrências ocorridas com os pacientes no último turno.

Esta passagem de informação é feita entre enfermeiro para médico, ou médico para médico, ou médico para enfermeiro, com objetivo de informar o que ocorreu e em qual horário ocorreu tal evento com cada um dos pacientes situados em seus respectivos leitos. As informações são repassadas de forma oral ou escrita para o receptor [1].

Esta rotina vivenciada pelo corpo médico algumas vezes torna-se desgastante e demorada, o que pode levar a uma possível omissão de algum evento importante ocorrido com o paciente ou talvez a uma troca de informação equivocada, podendo acarretar algum prejuízo na saúde do paciente [2].

Este projeto tende a melhorar estas trocas de informação na passagem de turno de modo prático e poupando tempo da equipe.
Um programa computacional foi desenvolvido onde enfermeiros e médicos podem introduzir as intercorrências de cada leito de forma rápida e segura. Segura pelo fato de ser registrado quem e em qual horário foram introduzidos no programa determinada ocorrência. Quando a equipe médica do próximo turno chegar, o monitoramento dos leitos será feito de forma rápida e prática.

\section{Materiais e métodos}

Para criação do programa proposto, foram utilizados notebook e dois softwares, o Visual Studio 2010 para desenvolvimento da interface e o sistema de banco de dados Microsoft SQL Server 2008 R2.

O Visual Studio é uma implementação da linguagem C\# pela Microsoft. O Visual Studio suporta o Visual C\# com um editor de código completo, compilador, modelos de projetos, designers e assistentes de código e outras ferramentas, um depurador poderoso e fácil de usar. A partir deste software foram criadas Windows Forms (janelas) as quais correspondem à interface do programa e foram configuradas de acordo com a aplicação desejada, como por exemplo a Tela de Login, Tela de Cadastro do Paciente e Tela de Consulta aos Leitos (Figuras 3, 6 e 7, respectivamente).

Observa-se a presença de campos que devem ser preenchidos pelo usuário do programa. Tais campos recebem informações que são armazenadas no Banco de Dados (SQL Server) conectado ao Visual Studio, ou seja, a partir desta conexão é possível criar, editar e visualizar as informações no programa.

O sistema de Banco de Dados trata-se de uma entidade em que é possível armazenar um conjunto de arquivos de dados, sendo possível acessá-los e atualizálos para o controle de dados e segurança do sistema. Foi utilizado, então, o software Microsoft SQL Server, um sistema de gerenciamento de banco de dados relacional desenvolvido pela Microsoft e o Microsoft SQL Server Management Studio para configurar, gerenciar e administrar todos os componentes dentro do Microsoft SQL Server, como as tabelas de dados e o relacionamento entre elas (Figura 1 e 2).

A fim de estabelecer um relacionamento entre as tabelas, foi realizada a configuração Foreign Key (chave estrangeira, em português). No contexto de banco de dados relacionais, uma chave estrangeira é um campo (ou conjunto de campos) em uma tabela que identifica 
exclusivamente uma linha de outra tabela. Em termos mais simples, a chave estrangeira é definida em uma segunda tabela, mas refere-se à chave principal na primeira tabela. Por exemplo, na Figura 2, a Tabela Paciente (tbPaciente) tem uma chave primária chamada idPaciente, a Tabela de Intercorrência (tbIntercorrencia) tem uma chave estrangeira que faz referência a idPaciente, a fim de identificar exclusivamente a relação entre as tabelas , assim como a Tabela de Medicação (tbMedicacao) tem a chave estrangeira relacionada à chave primária idPaciente da Tabela Paciente, estabelecendo-se o relacionamento entre elas.

\begin{tabular}{|l|}
\hline 7 tbUsuario \\
\hline idusuario \\
usuario \\
senha \\
repitaSenha \\
nivelAcesso \\
\hline thUsuarioTableAdapter \\
\hline Sal \\
\hline
\end{tabular}

Figura 1: Print screen da Tabela Usuário.

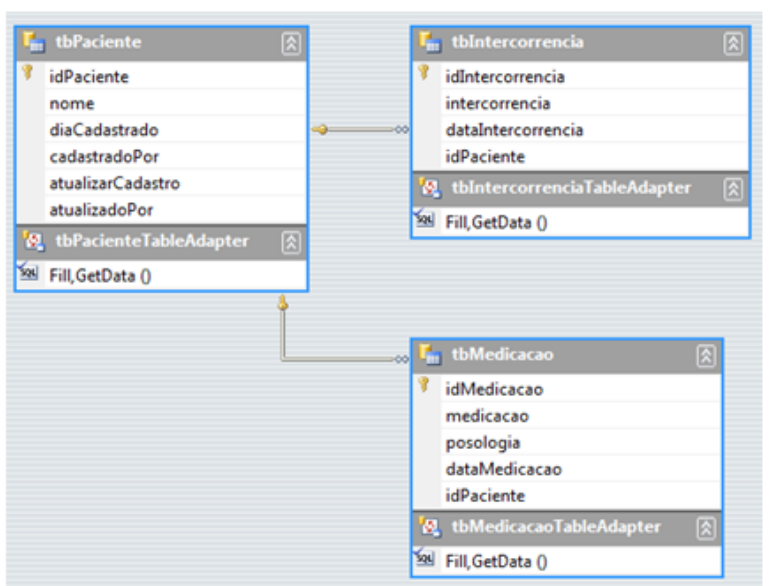

Figura 2: Print screen da tela de relacionamento entre Tabela do Paciente, Tabela de Intercorrência e Tabela de Medicação.

\section{Resultados}

O sistema desenvolvido foi batizado como MoniLeito (Sistema de Monitoramento de Leito) e só pode ser acessado após o usuário realizar o login, que é a primeira tela que o usuário se depara, conforme a Figura 3.

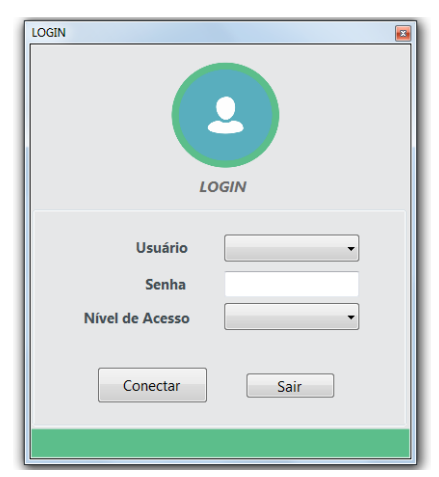

Figura 3: Print screen da tela de Login MoniLeito.

$\mathrm{O}$ usuário tem acesso às atividades do sistema de acordo com seu nível de acesso (Operador ou Administrador). As funcionalidades do sistema podem ser acessadas do ponto de vista do usuário de acordo com a Figura 4, para o operador, e de acordo com a Figura 5, para o administrador.

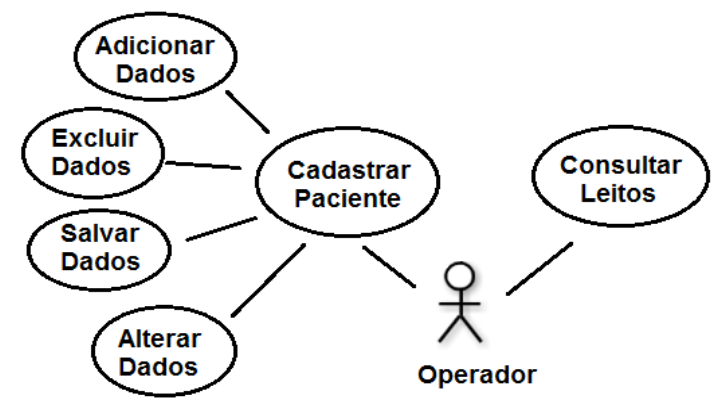

Figura 4: Diagrama de caso de uso do Operador (usuário comum).

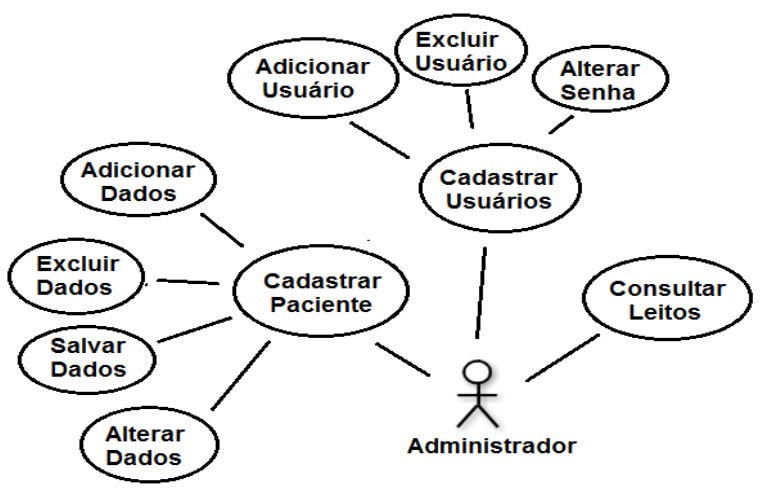

Figura 5: Diagrama de caso de uso do Administrador.

$\mathrm{O}$ cadastro de pacientes e as devidas informações referentes à ocupação do leito são realizados através da tela ilustrada na Figura 6. Onde o usuário preenche os campos como "nome do paciente", "medicação" administrada (posologia, data/hora) e "intercorrências" estabelecidas (data/hora) no determinado leito de acordo com o id de cada paciente. 


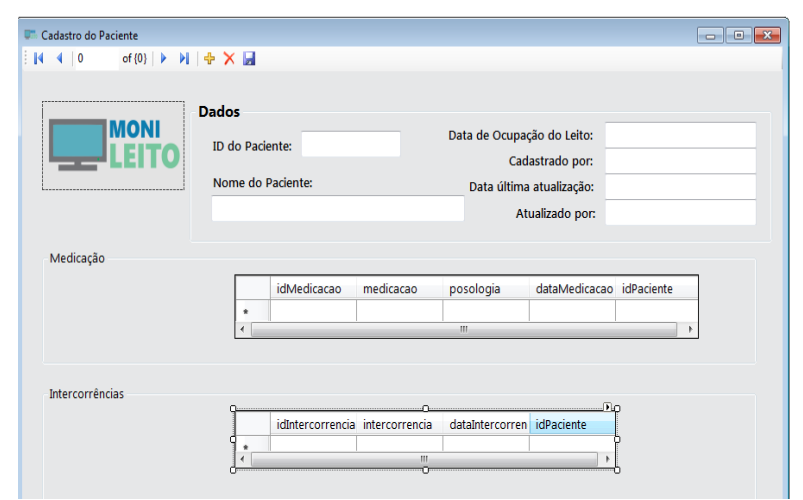

Figura 6: Print screen da tela de Cadastro de Paciente.

Os dados como "data de ocupação do leito" e "data da última atualização" são preenchidos automaticamente pelo próprio sistema e os dados como "cadastrado por" e "atualizado por" serão preenchidos automaticamente de acordo com o login do usuário.

Os dados cadastrados para cada paciente podem ser consultados através da tela ilustrada na Figura 7, onde o usuário entra com o número do leito que deseja visualizar (gerado de acordo com o id do paciente).

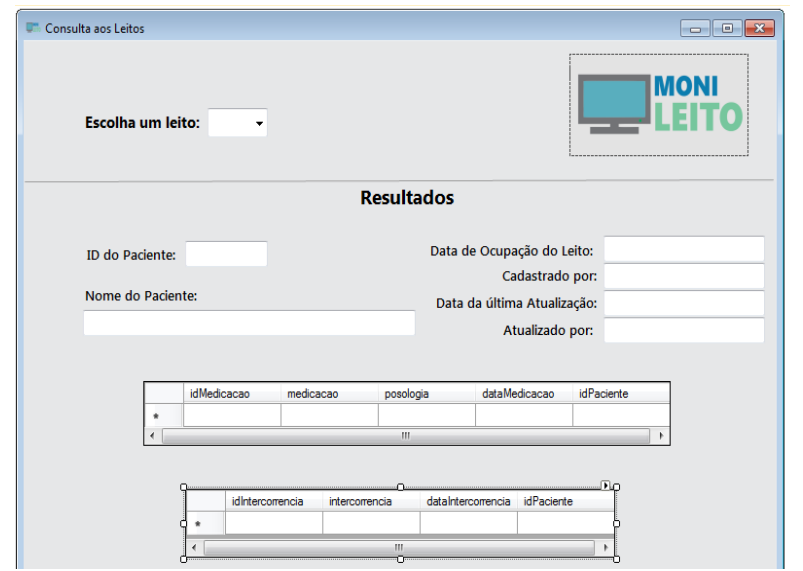

Figura 7: Print screen da tela de Consulta aos Leitos.

\section{Discussão}

Foram realizados testes relacionados à eficiência e eficácia do software para corrigir a presença de erros e verificar se os resultados estavam de acordo com o pretendido.

O sistema cumpre a função de permitir acesso aos profissionais cadastrados (operador ou administrador), para realizar atividades como cadastro, atualização e visualização dos dados referentes à ocupação do leito de um determinado paciente.

A segurança do sistema pode ser estabelecida através d o login com a finalidade de preservar os dados do paciente.

Os resultados desejados foram alcançados, mas como trabalhos futuros o sistema poderia ser apresentado a uma equipe de posto de saúde para então poder ser otimizado de acordo com as reais necessidades dos usuários e conter então outras ferramentas também importantes a um bom gerenciamento de leitos.

\section{Conclusão}

A organização do posto de saúde aliada a um sistema como o MoniLeito permite fácil acesso às informações referentes à ocupação de cada leito, possibilitando à equipe do posto médico obtenção organizada e melhor controle dos processos estabelecidos nos leitos.

Os dados gerados no sistema servem para permitir uma comunicação mais eficiente entre a equipe do posto de saúde e melhorar a rotatividade e atendimento aos leitos.

\section{Agradecimentos}

A Prof. Dra. Ana Claudia Patrocinio pelo suporte, correções e incentivo.

\section{Referências}

[1] Zoehler KG, Lima MADS. Opinião de auxiliares de enfermagem sobre a passagem de plantão. Rev Gaúcha Enferm. 2000 Jul;21(2):110-24.

[2]Camargo AT, Silveira MR, Matos SS, Stefanelli MC Passagem de plantão como instrumento de comunicação em instituição hospitalar. In: $6^{\circ}$ Simpósio Brasileiro de Comunicação em Enfermagem; 1998 p.74- 8; Ribeirão Preto, Brasil. Ribeirão Preto: Escola de Enfermagem de Ribeirão Preto da Universidade de São Paulo, 1998. 